\title{
Subsecond sintering of ice
}

\author{
Denes Szabo a) and Martin Schneebeli \\ WSL Swiss Federal Institute for Snow and Avalanche Research, CH-7260 Davos Dorf, Switzerland
}

(Received 11 January 2007; accepted 9 March 2007; published online 12 April 2007)

\begin{abstract}
Ice grains bond together in less than $1 \mathrm{~s}$. The tensile strength of the resulting bond was measured above $-25^{\circ} \mathrm{C}$ in the contact time range of $10-1000 \mathrm{~ms}$ as a function of temperature and contact load. The bond strength increases nonlinearly with time and with increasing temperature. The results indicate that the most likely mechanism of ice sintering on this time scale is the freezing of the liquidlike layer present on the surface of the ice. A model based on the plastic behavior of ice and the complete freezing of the entire contact patch well describes the observations. (C) 2007 American Institute of Physics. [DOI: 10.1063/1.2721391]
\end{abstract}

Sintering is a well known and widely studied phenomenon. ${ }^{1}$ It describes the formation of bonds between particles close to their melting point. Since ice on earth often exists close to its melting point, the sintering of ice has special importance. Many scientific disciplines including atmospheric science, ${ }^{2}$ snow metamorphism, ${ }^{3,4}$ icing of structures in cold climates, ${ }^{5}$ ice friction, ${ }^{6}$ and avalanche formation ${ }^{7}$ involve the sintering of ice. ${ }^{8-10}$ In some of these processes ice grains contact each other for a very short period of time. Previous researchers have studied the growth of bonds between ice grains, but most investigations have focused on bond formation at minute, hour, and multiday time scales. Gubler $^{11}$ and Fan et al. ${ }^{12}$ examined ice grains connected for $1 \mathrm{~s}$. Both studies have found a substantial tensile strength.

The mechanisms usually considered to contribute to ice sintering are slow and cannot be responsible for subsecond sintering. These mechanisms include vapor diffusion, surface diffusion, surface flow, volume diffusion, plastic flow, and grain boundary diffusion. ${ }^{13-16}$ The only mechanism that can account for a fast bond formation is the freezing of a liquid layer at the contact region. The freezing of water in a confined space is a very fast process. ${ }^{17}$ As a result a crystalline ice bond can quickly form after contact. The only remaining question is the origin of the liquid at the contact region. There are three possibilities: pressure melting, collisional melting, and the presence of a liquidlike layer on the ice surface.

Pressure melting fails to explain the sintering of ice because the pressure needed to change the melting point of ice far exceeds its mechanical strength. Except at temperatures close to the melting point (above $-1{ }^{\circ} \mathrm{C}$ ) the ice fractures before it would start to melt.

The impact between two ice particles can cause the temporary melting of the interfacial region as shown by Dash and Wettlaufer ${ }^{2}$ and Dash et al. ${ }^{18}$ In an impact, the highly localized plastic deformations generate a significant amount of heat. During the short time of the impact, there is no time to conduct the heat away from the contact region, hence resulting in an increase of temperature and possibly the melting of the ice. As the heat generated by the impact is conducted away the ice eventually refreezes, forming a bond between the particles. Although this is an intriguing conceptual model, it has not yet been shown that the heat produced

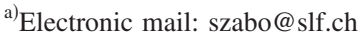

by an impact can be conducted away from the site fast enough for a bond to form.

The idea of the freezing of a liquidlike surface layer dates back to Faraday who performed a 20-year-long study on the adhesion of ice blocks starting in the $1840 \mathrm{~s} .{ }^{19,20} \mathrm{He}$ discovered that two ice blocks adhere to each other immediately when brought into contact. He explained this by the freezing of a water layer present on the surface of ice close to the melting point. His explanation was not well received by contemporary scientists due to the lack of theoretical and experimental evidences of a water layer on the ice surface. However, recent experimental techniques including ion and proton backscattering, x-ray scattering, low-energy electron diffraction, atomic force microscopy, as well as computer simulations show the existence of a disordered, liquidlike layer on the surface of different solids well below the melting point. ${ }^{21,22}$ Experiments show that in ice the thickness of the liquidlike layer decreases rapidly below the melting point but can still exist at $-40{ }^{\circ} \mathrm{C} .{ }^{5,23-26}$

We developed an apparatus that (1) brings two ice cones in contact with each other, (2) holds the cones together for a short period of time, and (3) separates the two cones while measures the force required to break the bond between them. We define this force as the sintering force. The experimental setup consists of a piezoelectric actuator, a force transducer, and sample holders. One of the ice cones is attached to the actuator, while the other is connected to microstages. This permits the precise relative positioning of the two cones. The whole arrangement is mounted in a rigid steel frame designed to prevent vibrations and to provide sufficient stiffness. Both air and sample temperatures were measured during the experiments. The former near the samples, the latter by thermocouples that were frozen directly into the samples during preparation. We prepared ice cones, $15 \mathrm{~mm}$ in length with a $3 \mathrm{~mm}$ radius of curvature at the tip, by freezing degassed clear mountain water (with a conductivity of $30 \mu \mathrm{S} / \mathrm{cm})$ in silicone molds at $-15^{\circ} \mathrm{C}$.

The experiments were conducted in a cold room, where the relative humidity was kept around 50\% independent of the temperature. We conducted several series of experiments, each at a different temperatures: $-1,-5,-12$, and $-23{ }^{\circ} \mathrm{C}$. At each temperature, we measured the contact time and contact load dependences of the sintering force in ranges of 20-1000 ms and 0.5-8 N, respectively.

What happens when two ice particles are pushed together with a constant force? Since the contact loads applied 


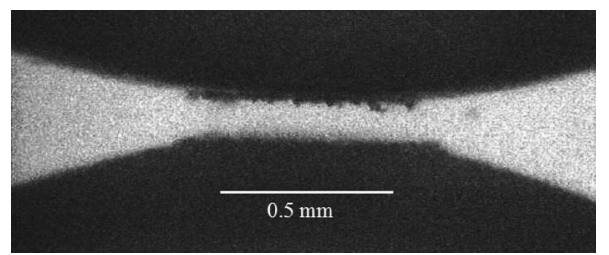

FIG. 1. Tip of the samples immediately after one experiment as seen by a charge couple device (CCD) camera equipped with a special macrolens. The samples lost their spherical shape indicating creep. This kind of distortion of the samples was most pronounced at high load and high temperature.

in our experiment are relatively high, the stress at the contact region exceeds the critical stress of the Huber-von Mises criterion. ${ }^{27}$ As a consequence, the ice undergoes extensive plastic deformations and the initially small contact area increases with time (see Fig. 1). The rate of the increase is determined by the plastic flow rate of the ice that depends on the stress and temperature. A time-independent, constant deformation rate of the specimen can be estimated from the power law creep of ice, ${ }^{28-30}$

$$
\dot{\varepsilon}_{\text {creep }}=C \sigma^{n} \exp \left(-\frac{\varepsilon}{k T}\right)
$$

where $C$ and $n$ are constants, $\sigma$ is stress, $\varepsilon$ is the experimental activation energy, $k$ is Boltzmann's constant, and $T$ is the absolute temperature. Usual values of the constants for relatively high load, high strain-rate experiments are $C=4.6$ $\times 10^{20} 1 / \mathrm{s}, n=3$, and $\varepsilon=1.33 \mathrm{eV}^{5,21}$

As an approximation, we can assume that the samples deform under a constant stress of $10 \mathrm{MPa}$, the high strainrate compressive strength of ice according to Barnes et $a l^{31}$ and Stephen. ${ }^{32}$ With this assumption, the creep rate given by Eq. (1) can be used to calculate the time dependence of the contact radius $a$,

$$
a(t)=\sqrt{R^{2}-\left(\sqrt{R^{2}-a_{0}^{2}}-\dot{\varepsilon}_{\text {creep }} l_{0} t\right)^{2}},
$$

where $a_{0}$ is the instantaneous radius of the contact patch due to elastic deformation and $l_{0}$ is assumed to be $3 \mathrm{~mm}$.

If we assume that the liquid present at the contact region (formed either by collisional melting or it is a liquidlike layer on the ice surface) completely freezes over the entire contact area, then the tensile strength of the bond $F_{\text {sintering }}$ is simply the tensile strength of ice $\sigma_{\text {tensile }}[=2 \mathrm{MPa}$ (Ref. 26)] multiplied by the area of contact $F_{\text {sintering }}(t)=\sigma_{\text {tensile }} a(t)^{2} \pi$. We can obtain the time dependence of the sintering force by combining Eqs. (1) and (2). It is also possible to derive the contact load dependence of the sintering force by calculating the strain rates based on the stress obtained from the Herzian contact theory. ${ }^{27}$

Figure 2 shows the sintering force as a function of contact time at different temperatures. Sintering exists even at the lowest temperature and lowest contact time. The sintering force actually seems to converge to the same value of around $0.04 \mathrm{~N}$ at $0 \mathrm{~ms}$ independent of temperature. As expected, the sintering force increases with increasing contact time. However, the rate of increase decreases rapidly with contact time at a certain temperature. The change is most pronounced in the $0-200 \mathrm{~ms}$ range and slows down drastically on the time scale of seconds. This is in good agreement with the observations of Fan et al. ${ }^{12}$

Sintering is highly temperature dependent. For a given contact time, the sintering force increases with temperature

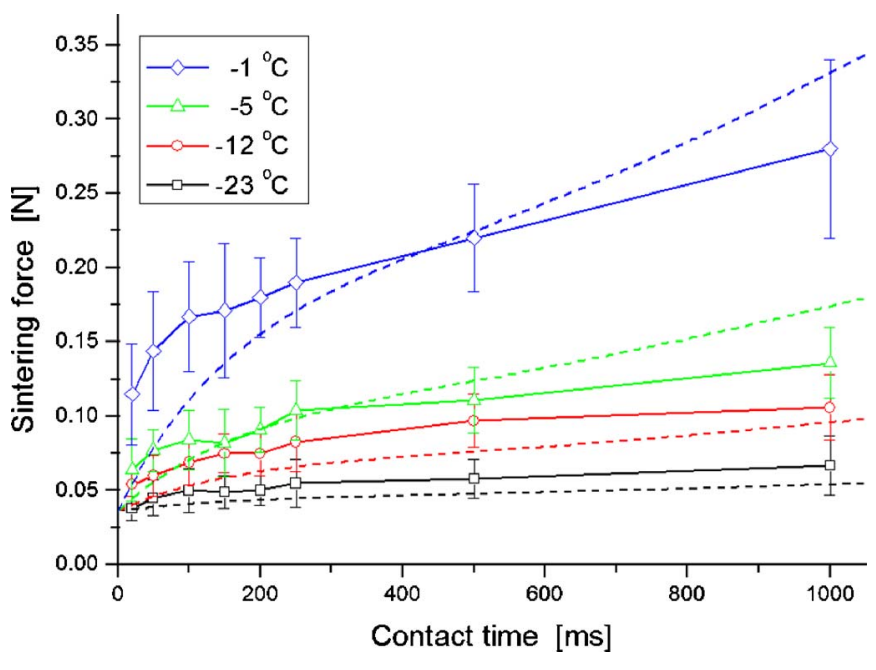

FIG. 2. (Color online) Sintering force vs contact time at different temperatures. Model predictions based on the freezing of the liquidlike layer (single lines) and experimental results (lines and symbols) are shown. The contact force was $2 \mathrm{~N}$ in all experiments. The error bars represent the standard deviation of several experiments.

and it becomes especially pronounced close to the melting point. This is in good agreement with our everyday experience, as it is much easier to make a snow ball at temperatures close to zero.

The calculated sintering force curves are also shown in Fig. 2. Despite the assumptions and approximations, it predicts the time dependence as well as the magnitude of the sintering force surprisingly well. Moreover, it predicts properly the existence of a temperature independent minimum value at $0 \mathrm{~ms}$ that, according to the model, is an effect of an instantaneous elastic deformation leading to a minimum contact area.

Figure 3 shows the sintering force as a function of contact load at different temperatures. Except for some deviation around $2 \mathrm{~N}$ at low temperatures, the higher the load the higher the sintering force. This observation is consistent with our conceptual model as a higher load results in a larger contact area, and thus, a stronger bond.

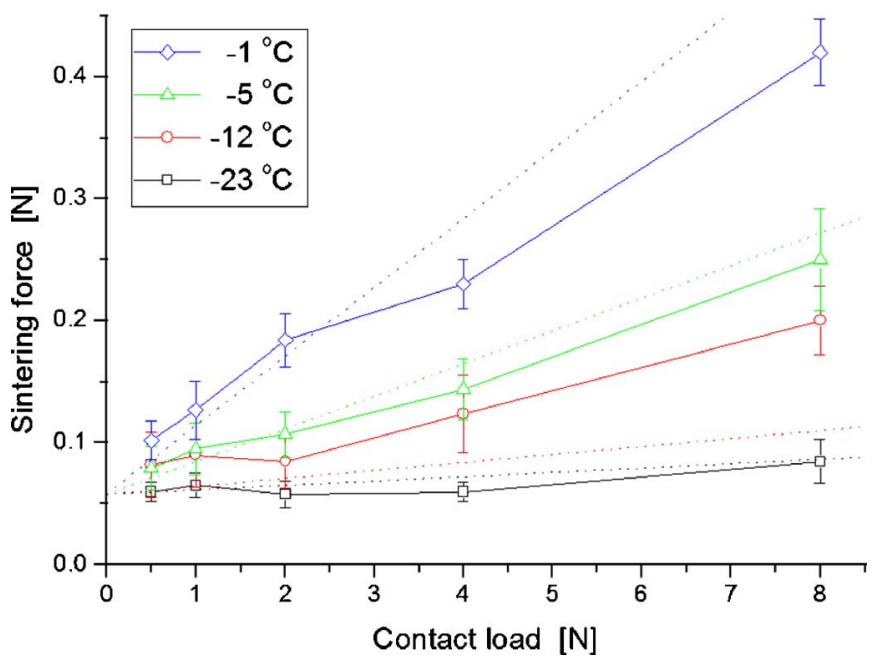

FIG. 3. (Color online) Sintering force vs contact load at different temperatures. Model predictions based on the freezing of a premelted layer (dashed lines) and experimental results (solid lines and symbols) are shown. The contact time was $250 \mathrm{~ms}$ in all experiments. Several samples have been measured at each point. Error bars represent standard deviation. 
At a certain temperature the sintering force depends linearly on contact load. At each temperature the sintering force seems to converge to a nonzero value at $0 \mathrm{~N}$ (ranging between 0.06 and $0.1 \mathrm{~N}$ for -23 and $-1{ }^{\circ} \mathrm{C}$, respectively). This can be explained by a liquidlike layer on the surface; when the surfaces approach each other first the two liquid layers come into contact. Before the solid bodies come into contact (i.e., before we measure a nonzero contact force) a contact patch already exists. The freezing of the liquid layer in this small contact area forms a bond and manifests itself as a sintering force when the contact force is zero. This idea is also supported by the results of atomic force microscopy studies on ice. ${ }^{33}$ In these experiments the cantilever experiences an attractive force as it approaches the ice surface and it abruptly jumps into the surface due to capillary forces from the liquidlike layer. ${ }^{34}$

Model predictions are also plotted in Fig. 3. The model predicts a linear dependence that is in accordance with the experiments. The theoretical curves are fairly close to the experimental ones except for $-12{ }^{\circ} \mathrm{C}$, where the model underestimates the sintering force. The model does not predict a sintering force at zero contact force. A constant force of $0.058 \mathrm{~N}$ was added to the model curves at each temperature in order to obtain a more realistic fit.

In conclusion, we measured the subsecond sintering of ice in air. We found that ice sintering is a relevant process on the millisecond time scale. The effect is most pronounced in the first $200 \mathrm{~ms}$ and temperatures close to the melting point of ice. Based on the experimental results we concluded that the basic mechanism of ice sintering on this time scale is the freezing of a liquid layer at the contact region. The contact time, contact load, and temperature dependencies of the sintering force are the consequences of the dependence of the plastic deformation rate of the ice on these quantities.

${ }^{1}$ R. M. German, Sintering Theory and Practice (John Wiley, New York, 1996).

${ }^{2}$ J. G. Dash and J. S. Wettlaufer, Can. J. Phys. 81, 201 (2003).

${ }^{3}$ R. L. Brown, M. Q. Edens, M. Barber, and A. Sato, in Snow Engineering:
Recent Advances, edited by N. Izumi, T. Nakamura, and R. L. Sack (Balkema, Rotterdam, 1997), p. 41.

${ }^{4}$ S. C. Colbeck, U.S. Army Cold Regions Research and Engineering Laboratory Research Report No. 97-10, 1997.

${ }^{5}$ V. F. Petrenko and R. W. Whitworth, Physics of Ice (Oxford University Press, Oxford, 1999).

${ }^{6}$ N. Maeno, M. Arakawa, A. Yasutome, N. Mizukami, and S. Kanazawa, Can. J. Phys. 81, 241 (2003).

${ }^{7}$ J. Schweizer, J. B. Jamieson, and M. Schneebeli, Rom. J. Phys. 41, 1016 (2003).

${ }^{8}$ W. Zhang and J. H. Schneibel, Acta Metall. Mater. 43, 4377 (1995).

${ }^{9}$ S. C. Colbeck, J. Appl. Phys. 84, 4585 (1998).

${ }^{10}$ E. E. Adams, D. A. Miller, and R. L. Brown, J. Appl. Phys. 90, 5782 (2001).

${ }^{11}$ H. Gubler, J. Glaciol. Geocryol. 28, 457 (1982).

${ }^{12}$ X. Fan, P. Ten, C. Clarke, A. Bramley, and Z. Zhang, Powder Technol. 131, 105 (2003)

${ }^{13}$ W. D. Kingery, J. Appl. Phys. 31, 833 (1960).

${ }^{14}$ D. Kuriowa, U.S. Army Cold Regions Research and Engineering Laboratory Research Report No. 861962.

${ }^{15}$ P. V. Hobbs and B. J. Mason, Philos. Mag. 9, 181 (1964).

${ }^{16}$ N. Maeno and T. Eniuma, J. Phys. Chem. 87, 4103 (1983).

${ }^{17}$ D. H. Dolan and Y. M. Gupta, J. Chem. Phys. 121, 9050 (2004).

${ }^{18}$ J. G. Dash, B. L. Mason, and J. S. Wettlaufer, J. Geophys. Res. 106, 20395 (2001).

${ }^{19}$ M. Faraday, Philos. Mag. 17, 162 (1859).

${ }^{20}$ M. Faraday, Philos. Mag. 18, 440 (1860).

${ }^{21}$ H. Löwen, Phys. Rep. 237, 249 (1994).

${ }^{22}$ A. A. Chernov, Prog. Cryst. Growth Charact. Mater. 26, 195 (1993).

${ }^{23}$ J. S. Wettlaufer, Philos. Trans. R. Soc. London, Ser. A 357, 3403 (1999).

${ }^{24}$ S. Engemann, H. Reichert, H. Dosch, J. Bilgram, V. Honkimaki, and A. Snigirev, Phys. Rev. Lett. 92, 205701 (2004).

${ }^{25}$ I. A. Ryzhkin and V. F. Petrenko, Phys. Rev. B 65, 012205 (2002).

${ }^{26}$ B. F. Henson and J. M. Robinson, Phys. Rev. Lett. 92, 246107 (2004).

${ }^{27}$ K. L. Johnson, Contact Mechanics (Cambridge University Press, Cambridge, 1985).

${ }^{28}$ P. V. Hobbs Ice Physics (Clarendon, Oxford, 1974).

${ }^{29}$ J. J. Petrovic, J. Mater. Sci. 38, 1 (2003).

${ }^{30}$ T. J. O. Sanderson Ice Mechanics: Risks to Offshore Structures (Graham and Trotman, London, 1988).

${ }^{31}$ P. Barnes, D. Tabor, and J. C. F. Walker, Proc. R. Soc. London, Ser. A 324, 127 (1971).

${ }^{32}$ J. J. Stephen, J. Phys. Chem. B 101, 6099 (1997).

${ }^{33}$ A. Döppenschmidt and H. J. Butt, Langmuir 16, 6709 (2000).

${ }^{34}$ B. Pittenger, D. J. Cook, C. R. Slaughterbeck, and S. C. Fain, J. Vac. Sci. Technol. A 16, 1832 (1998). 